Review Article

\title{
Side Population: Its Use in the Study of Cellular Heterogeneity and as a Potential Enrichment Tool for Rare Cell Populations
}

\author{
Elize Wolmarans $\mathbb{D}^{1},{ }^{1}$ Sulette Nel $\mathbb{D},{ }^{2}$ Chrisna Durandt $\left(\mathbb{D},{ }^{1}\right.$ Juanita Mellet $\mathbb{D}{ }^{1}$, \\ and Michael S. Pepper (i) ${ }^{1}$ \\ ${ }^{1}$ Institute for Cellular and Molecular Medicine, Department of Immunology and South African Medical Research Council Extramural \\ Unit for Stem Cell Research and Therapy, Faculty of Health Sciences, University of Pretoria, Pretoria, South Africa \\ ${ }^{2}$ Department of Oral Pathology and Oral Biology, School of Dentistry, Faculty of Health Sciences, University of Pretoria, \\ Pretoria, South Africa
}

Correspondence should be addressed to Michael S. Pepper; michael.pepper@up.ac.za

Received 24 August 2018; Revised 7 November 2018; Accepted 14 November 2018; Published 6 December 2018

Guest Editor: Zhaoping Ding

Copyright (c) 2018 Elize Wolmarans et al. This is an open access article distributed under the Creative Commons Attribution License, which permits unrestricted use, distribution, and reproduction in any medium, provided the original work is properly cited.

\begin{abstract}
There is still much to learn about the cells used for cell- and gene-based therapies in the clinical setting. Stem cells are found in virtually all tissues in the human body. As a result, cells isolated from these tissues are a heterogeneous population consisting of various subpopulations including stem cells. Several strategies have been used to isolate and define the subpopulations that constitute these heterogeneous populations, one of which is the side population (SP) assay. SP cells are identified by their ability to efflux a fluorescent dye at a rate that is greater than the main cell population. This elevated rate of dye efflux has been attributed to the expression of members of the ATP-binding cassette (ABC) transporter protein family. SP cells have been identified in various tissues. In this review, we discuss the research to date on SP cells, focussing on SP cells identified in haematopoietic stem cells, adipose-derived stromal cells, and dental pulp.
\end{abstract}

\section{Introduction}

Stem cells are increasingly being considered for their use in cell- and gene-based therapies, which constitute the most recent phase of the biotechnology revolution in medicine. Stem cells can be defined as a population of undifferentiated cells capable of proliferation and self-renewal whose differentiated progeny constitute all of the cell types of the human body [1-6].

Stem cells exist in a tightly regulated microenvironment referred to as a niche, dispersed between differentiated cells in various tissues in the body [7]. The stem cell niche does not refer to a specific location but rather to a microenvironment which provides a milieu in which the cells receive various stimuli that determine their fate or differentiation status [8]. As a result, stromal cells isolated from tissues in the human body are a heterogeneous population, consisting of subpopulations including a subpopulation of true stem cells. Various strategies have been used to isolate and define these subpopulations. In general, stem cell biology is limited by the lack of specific cell surface markers that unambiguously label the cells [9] and most investigators agree that the current "stem cell pool" consists of true (primitive) stem cells and progenitors at different stages of differentiation.

One of the methods currently used in an attempt to identify primitive stem cell subpopulations is the side population (SP) assay. The SP assay is based on the ability of cells to actively efflux a fluorescent dye [7,10-13]. The cells are incubated for a predetermined period of time with a fluorescent dye that passively diffuses across the cell membrane. After the incubation period, the cell populations are interrogated using flow cytometry to detect and quantify the subpopulation with lower intracellular levels of the substrate, suggesting that these cells have the ability to actively efflux the 


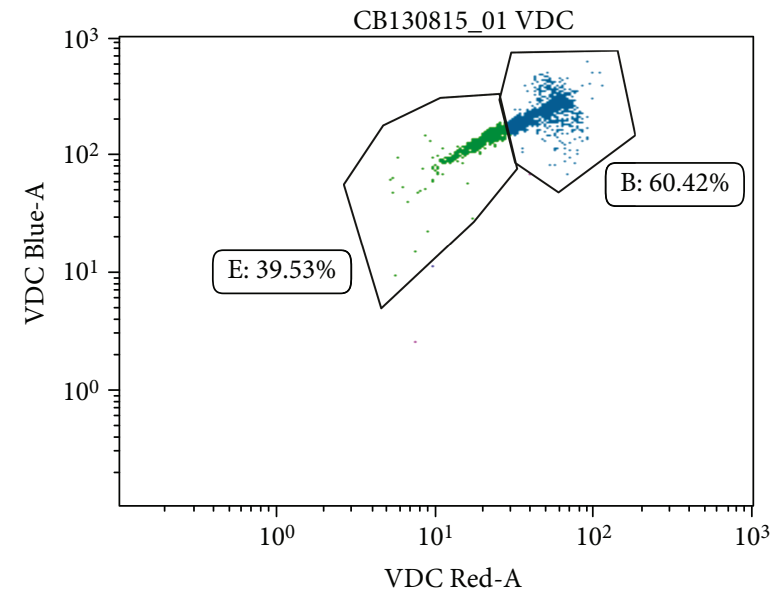

(a)

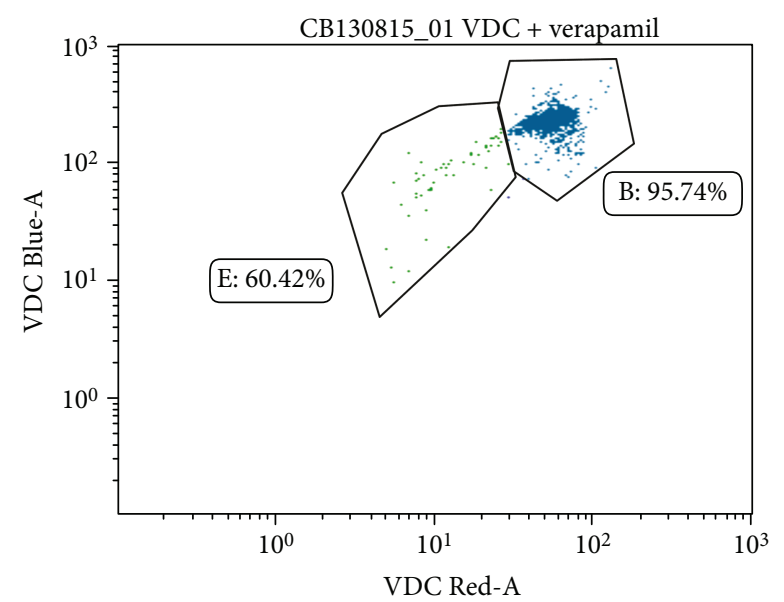

(b)

FIgURE 1: Representation of the SP in flow cytometric dot plots. (a) Dot plot showing the fluorescence pattern of hematopoietic stem and progenitor cells (HSPCs) freshly isolated from the umbilical cord blood that has been stained and incubated with the fluorescent dye VDC Violet. The main population of cells (gate B) shows greater fluorescence intensity than the cells in the tail (gate E). This tail is known as the SP and represents a subpopulation of cell with greater efflux ability than the rest of the cells. (b) Dot plot showing the disappearance of the SP tail when HSPCs are incubated with VDC Violet and the ABC transporter blocker, verapamil. Cells that were part of gate E have now moved up to join the main population of cells. This is due to the blocking effect of verapamil, which prevents the dye from being effluxed by the cells.

fluorescent substrates at a greater rate compared to the other cells. Fluorescent dyes, such as Hoechst 33342 and Vybrant ${ }^{\circledR}$ DyeCycle $^{\mathrm{TM}}$ (VDC) Violet, are usually the substrates used in the flow cytometric SP assay.

The assay makes use of the broad emission spectrum (ranging from around $350 \mathrm{~nm}$ to $650 \mathrm{~nm}$ ) of these fluorescent substrates by measuring the changes in intracellular fluorescent emission at the optimal wavelength $(460 \mathrm{~nm}$; blue spectrum) as well as at the tail end of the emission spectrum $(630 \mathrm{~nm}$; red spectrum) [7, 10-13]. This subset of cells with decreased levels of fluorescent dye is termed the SP (Figure 1). The elevated rate of dye efflux seen in SP cells has been attributed to the expression of members of the ATP-binding cassette $(\mathrm{ABC})$ transporter protein family.

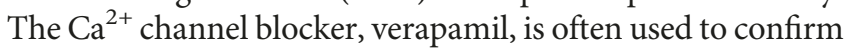
that the decreased fluorescence intensity observed in the SP subpopulation is due to active efflux of the fluorescent substrate (Figure 1(b)). Verapamil blocks the activity of efflux proteins by reducing the membrane potential of the cells [14].

\section{ABC Transporters}

$\mathrm{ABC}$ transporters represent one of the largest families of membrane transport proteins and are expressed in all organisms $[7,15,16]$. The human $\mathrm{ABC}$ transporter family consists of 50 proteins which are divided into seven subfamilies - A to G-based on similarity in gene structure, order of the domains, and sequence homology [15-19]. Most human $\mathrm{ABC}$ transporters are primary active transporters, coupling the binding and hydrolysis of ATP to movement of solutes across the plasma membrane and the intracellular membranes of the Golgi apparatus, endoplasmic reticulum (ER), peroxisomes, and mitochondria [7, 15, 17]. They are known for their role in maintaining cellular homeostasis, transporting lipids and organic anions, and facilitating iron metabolism [7, 16, 18-20].

$\mathrm{ABC}$ transporters also play a vital role in cellular/tissue defence due to their ability to actively efflux various xenobiotics out of the cells $[7,16,18-20]$. The three most well-studied transporters known for their efflux capabilities include P-glycoprotein (P-gp; $A B C B 1$ ), multidrug resistanceassociated protein 1 (MRP1; $A B C C 1)$, and breast cancer resistant protein (BCRP; ABCG2) [11, 21-24].

\section{Side Population and Stem Cells}

Several studies have suggested that the degree of efflux activity of SP cells is inversely correlated to their maturity, with the most primitive cells (the stem/progenitor cells) having the greatest efflux activity due to the high concentration of efflux proteins on their surface $[13,25,26]$. It is hypothesized that $\mathrm{ABC}$ transporter expression is functionally connected to the pluripotency/multipotency of stem or progenitor cell populations and may also play an important physiological role $[13,24,27]$. It is believed that primitive, undifferentiated cells have an increased ability to efflux certain toxins, including fluorescent substrates, as a mechanism to protect themselves against potential harmful xenobiotics [28]. These theories are supported by studies comparing the expression of $\mathrm{ABC}$ transporters in embryonic stem cell lines and MSCs. It has been reported that different cell types have characteristic expression patterns of $\mathrm{ABC}$ transporters which depend on the cell's maturation state, further supporting the idea that multiple $\mathrm{ABC}$ transporter proteins may facilitate the pluripotency of the stem cell population $[20,27]$.

However, the terms "side population" and "stem cell" should not be used interchangeably, as SP cells and stem cells are not necessarily the same cells [10]. It was found that 
TABLE 1: List of tissues in which the SP has been identified.

\begin{tabular}{|c|c|c|}
\hline Source & Species & References \\
\hline \multicolumn{3}{|l|}{ Hematopoietic stem/stromal cells } \\
\hline Bone marrow & $\begin{array}{c}\text { Human } \\
\text { Murine } \\
\text { Rhesus monkey }\end{array}$ & $\begin{array}{l}([12] ;[32] ;[33] ; \\
[21] ;[24] ;[13])\end{array}$ \\
\hline Peripheral blood & Human & [34] \\
\hline Umbilical cord blood & Human & [35] \\
\hline \multicolumn{3}{|l|}{ Embryonic stem cells } \\
\hline Immortalized cell lines & $\begin{array}{l}\text { Mouse } \\
\text { Human }\end{array}$ & $([20] ;[31])$ \\
\hline \multicolumn{3}{|l|}{ Multipotent stromal/stem cells } \\
\hline Cells derived from ESC lines & Murine & $([20] ;[31])$ \\
\hline Bone marrow & Canine & {$[36]$} \\
\hline $\begin{array}{l}\text { Neural tissue } \\
\text { (neural stem cells) }\end{array}$ & $\begin{array}{l}\text { Human } \\
\text { Murine }\end{array}$ & $([37] ;[7] ;[38])$ \\
\hline Dental pulp & $\begin{array}{l}\text { Human } \\
\text { Canine } \\
\text { Porcine }\end{array}$ & $\begin{array}{l}([9] ;[36] ;[39] ; \\
[40] ;[41] ;[42])\end{array}$ \\
\hline Cardiac tissue & $\begin{array}{l}\text { Human } \\
\text { Murine }\end{array}$ & $\begin{array}{c}([20] ;[43] ;[44] ; \\
\quad[45] ;[38])\end{array}$ \\
\hline Lung tissue & $\begin{array}{l}\text { Human } \\
\text { Murine }\end{array}$ & $([46] ;[47] ;[38])$ \\
\hline Muscle tissue & Murine & $\begin{array}{l}([48] ;[24] ;[49] ; \\
[50] ;[51] ;[38])\end{array}$ \\
\hline Adipose tissue & $\begin{array}{l}\text { Human } \\
\text { Murine } \\
\text { Rat } \\
\text { Canine }\end{array}$ & $\begin{array}{c}([36] ;[52] ;[29] ; \\
\quad[53] ;[54])\end{array}$ \\
\hline Epidermis (keratinocytes) & Human & {$[55]$} \\
\hline Endometrium & $\begin{array}{l}\text { Human } \\
\text { Murine }\end{array}$ & $([30] ;[56])$ \\
\hline
\end{tabular}

subpopulations within the SP have different immunophenotypic markers and rates of clonogenic expansion [29, 30]. It is therefore generally accepted that the SP is still heterogeneous in nature and may only contain a subpopulation of stem cells with efflux ability $[10,30]$. The SP phenotype should thus be viewed as a useful enrichment strategy for the isolation of potential stem or progenitor cells from a heterogeneous population, rather than a characteristic of primitive stem cells in general. In addition, it should be taken into consideration that the dye efflux ability may not be a common property of all stem cell populations [11]. For example, Zeng and colleagues reported that undifferentiated Oct $4^{+}$human embryonic stem cells (H9) were Hoechst ${ }^{+}$whilst the Hoechst ${ }^{-}$population also contained spontaneously differentiated H9 cells [31].

The SP has been identified in various tissues (see Table 1). Here we review the research conducted to date on selected stem/stromal cell populations with a specific focus on the following:

(a) Characterization of SP cells

(b) SP cells in in vitro and/or in vivo environments (c) Expression of $\mathrm{ABC}$ transporters and their possible roles in the SP with a focus on P-gp, MRP1, and BCRP

3.1. Side Population in Hematopoietic Stem Cells. In the early 1990 s, several investigators observed and reported on the presence of a subpopulation ("side population") in murine hematopoietic stem cells (mHSCs) that have the ability to actively efflux fluorescent dyes such as Hoechst 33342 and/or Rhodamine 123 [57, 58]. Goodell and colleagues improved the method used to detect these cells in 1996 [12]. The SP cells isolated from mHSCs were characterized on the basis of expression of defined mHSC cell surface markers such as $\mathrm{Lin}^{-}$, c-Kit $(\mathrm{CD} 117)^{+}$, and Sca- $1^{+}[12,32$, 33]. SP cells isolated from mHSCs were reported to have greater stemness properties when compared to the main population of cells. The SP cells showed increased self-renewal capacity in both cobblestone area-forming cell (CAFC) assay in vitro and long-term competitive repopulation experiments in vivo $[12,33]$.

Following the observation that the SP is usually lost after cells are treated with verapamil, a $\mathrm{Ca}^{+}$channel and known $\mathrm{P}$ gp blocker, it was assumed that the $\mathrm{ABC}$ transporter protein $\mathrm{P}$-gp is responsible for Hoechst dye efflux [13, 24, 32]. Investigations have however revealed that even though mHSCs express various $A B C$ transporters, $B C R P$ is the only protein associated with the dye efflux properties of the SP phenotype [24]. It is believed that the expression of $A B C B 1$ and the presence of P-gp protein may not be needed for the efflux ability of these cells but may play an important physiological role in progenitor cells $[21,24]$.

In humans, the SP phenotype has been discovered in HSCs (hHSCs) isolated from the peripheral blood [34, 59], umbilical cord blood [35], and bone marrow [13].

Scharenberg studied the expression of the three best known efflux proteins associated with the $A B C B 1, A B C C 1$, and $A B C G 2$ genes in SP cells from hHSCs isolated from the bone marrow. Similar to mHSCs, ABCG2, which codes for BCRP, was the predominant efflux transporter gene expressed in hHSC SP cells [13].

While characterizing SP cells from hHSCs isolated from umbilical cord blood, Storms et al. [35] reported heterogeneity within the isolated SP cells with distinct $\mathrm{CD} 34^{+}$and CD34- populations [35]. When comparing these two subpopulations with regard to immunophenotype and in vitro behaviour, they found that both $\mathrm{Lin}^{-} \mathrm{CD} 34^{+}$and $\mathrm{Lin}^{-} \mathrm{CD} 34^{-}$ SP subpopulation had a similar phenotype with cells negative for CD38, Thy-1, CD33, CD45RA, and CD71 and intermediate expression levels of HLA-DR [35]. However, the $\mathrm{Lin}^{-} \mathrm{CD} 34^{+}$subpopulation resulted in enriched myeloid and erythroid progenitors in both short-term and 5-week longterm colony-forming unit (CFU) assays while the $\mathrm{Lin}^{-} \mathrm{CD} 34^{-}$ SP subpopulation failed to grow in standard short-term or long-term myeloerythroid CFU assays [35]. The SP cells in hHSCs derived from peripheral blood were also reported to be CD $34^{+}$and CD $38^{-}$. These SP cells displayed greater proliferative capacity and generated more clonogenic progenitors during culturing and also showed greater engraftment capabilities in xenotransplantation studies $[34,59]$. 
3.2. Side Population in Adipose-Derived Stromal Cells. Adipose-derived stromal cells (ASCs) contain a subpopulation of multipotent stem/progenitor cells [2]. Over the last decade, the use of ASCs in cell-based therapies has gained increasing attention since these cells are found in abundance in adipose tissue, can easily be isolated with minor donor site morbidity, and, reportedly, have promising regenerative properties [60].

A SP has been identified in murine $[29,52,53]$ and human $[52,54,61]$ ASCs.

SP cells derived from murine adipose tissue have been shown to differentiate in vitro into myogenic, osteogenic, chondrogenic, and adipogenic lineages [29, 53]. Andersen et al. [29] identified SP cells in freshly isolated ASCs (known as the stromal vascular fraction (SVF)) isolated from mouse gonadal fat pads. Using immunophenotypic analysis, they identified two subpopulations within the SP: cells positive and cells negative for the common leukocyte marker, CD45 [29]. This once again highlights to the notion that the SP is not a homogenous population. The $\mathrm{CD} 45^{-} \mathrm{SP}$ subpopulation was enriched with cells expressing the ABCG2 gene (along with other transcripts such as CD31, CD106, CD133, and endoglin) and showed greater efflux capacity when compared to the $\mathrm{CD} 45^{+}$SP subpopulation [29]. $A B C B 1$ was mainly expressed by cells in the $\mathrm{CD} 45^{+}$subpopulation while $A B C C 1$ was expressed in both subpopulations [29].

The SP cells isolated from mASCs have also been studied in various wound-healing models. Andersen et al. created knife-cut lesions in the M. gastrocnemius of NMRI mice. They showed that when CD45 ${ }^{-}$SP cells from ASCs (ASC$\mathrm{SP})$ were injected directly into the lesion, the $\mathrm{CD} 45^{-} \mathrm{SP}$ cells showed better intramuscular engraftment compared to SVF [29]. Not only did the CD45- SP cells engraft better but they also differentiated into myotubes whereas only mononuclear cells were observed in the lesion area in the mice that were injected with SVF cells [29]. Ramos et al. studied the wound-healing abilities of SP-ASCs which were injected intradermally into NOD/SCID mice which had received a $3 \mathrm{~mm}$ incision through the epidermis and dermis [53]. They reported complete healing and regeneration of dermis and epidermis layers of the mice within 7 days with minimal scar formation compared to the control mice, which were injected with only PBS [53]. In 2012, Sayre and Silva [52] patented a method for using ASC-SP cells for promoting tissue regeneration. The patent states that ASC-SP cells can be isolated and transplanted via intradermal injection adjacent to the wound site, aiding in tissue regeneration in both acute and chronic wounds [52].

Little has been published on SP cells derived from human (h) ASCs with regard to their characterization or the expression of $\mathrm{ABC}$ transporters. The literature has mainly focussed on the therapeutic efficacy of SP cells in vitro and in vivo. Du et al. [61] studied the ability of cultured hASCs to differentiate into keratinocytes in vitro. They used a SP assay to indicate the presence of multipotent adult stem cells in ASC cultures but did not conduct further experiments to characterize the identified SP cells [61]. In their patent, Sayre and Silva [52] identified SP cells from freshly isolated mouse and human ASCs, stating that their method could be implemented with ASCs from both species. SP cells derived from hASC reportedly had an immunophenotype of $\mathrm{Lin}^{-}, \mathrm{Sca}-1^{+}, \mathrm{CD} 90^{+}, \mathrm{CD} 34^{+/ \text {low }}, \mathrm{CD} 13^{+/ \text {low }}, \mathrm{CD} 117^{-}$, and $\mathrm{CD} 18^{+/ \text {low }}$ [52]. Supronowicz et al. [54] studied human ASC-SP cells in tissue engineering applications; these authors used immunophenotypic markers, CD90 and CD117, in conjunction with Hoechst staining, to identify SP cells. They found that human ASC-SP cells were able to attach and proliferate on demineralized bone matrix (DBM) and to differentiate into the osteogenic lineage in vitro [54]. Further in vivo studies showed that when added to DBM grafts in a rat ectopic pouch model, hASC-SP cells enhanced bone formation [54].

3.3. Side Population in Dental Pulp. The dental pulp consists of highly vascular tissue that plays an important role in tooth homeostasis. This tissue is rich in natural stem and progenitor cells that play a direct role in innate healing. Cell therapies promoting the regeneration of pulp tissue have the potential to treat pulpitis or periapical disease, assuring longevity of teeth and improved quality of life [36]. In 2006, Iohara et al. proposed that dental pulp SP cells are enriched for stem cell properties [39]. Since then, SP cells have been identified in the dental pulp of several species including pigs [39], canines [36], and humans [9, 42].

Ishizaka and colleagues [36] isolated SP cells from canine dental pulp and compared these cells to mesenchymal stromal cell side population (MSC-SP) cells isolated from canine bone marrow and adipose tissue. Due to their gating strategy, SP cells, from all three tissues, did not express CD31 [36]. SP cells from all three tissues demonstrated CFU ability and were $\mathrm{CD} 29, \mathrm{CD} 44, \mathrm{CD} 73$, and CD90 positive [36]. At the molecular level, SP cells from all three tissues expressed the stem cell markers Sox2, Tert, BMI1, CXCR4, Stat3, and Oct4 [36]. The regenerative capacity of SP cells isolated from dental pulp was further studied using an in vivo pulp regeneration model. SP cells from the three canine tissues were compared, and all were able to affect regeneration of pulplike tissue; bone marrow $\mathrm{CD} 31^{-} \mathrm{SP}$ cells produced the smallest amount of regenerated tissue [36].

$\mathrm{CD} 31^{-}$SP cells obtained from porcine dental pulp tissue had more potent angiogenic, vasculogenic, neurogenic, and regenerative potential compared to $\mathrm{CD} 31^{-} \mathrm{SP}$ cells isolated from the bone marrow and adipose tissue [62]. Furthermore, condition medium from porcine pulp $\mathrm{CD} 31^{-} \mathrm{SP}$ cell cultures exhibited a strong stimulatory effect on angiogenesis and inhibition of apoptosis in pulp regeneration, which may be due to higher expression of MCP1 and CXCL14 in dental pulp SP cells [40].

In humans, SP isolated from dental pulp has increased CFU ability compared to main population cells [9]. The SP cells were able to differentiate in vitro into multiple cell lineages including odontoblasts/osteoblast-like cells, adipocytes, neural-like cells, and endothelial cells [9]. These SP cells expressed stem cell markers, including the Oct4, BMI1, and Stat 3 genes, at higher rates when compared to main population cells [9].

Efflux-related heterogeneity is dependent on $\mathrm{ABC}$ transporter proteins. Wang et al. [9] considered the expression 
of BCRP and found that only SP cells, and not main population cells, expressed BCRP. It was also found that this expression decreased over time [9]. In situ immunohistochemistry investigations demonstrated that BCRP is mainly expressed in endothelial cells of some microvessels and in odontoblasts at the periphery of the dental pulp $[9,63]$. In earlier studies, Wang et al. also described BCRP expression in a small fraction of dental pulp cells (DPCs) from both deciduous (3.6 $\pm 0.8 \%$ DPCs expressed BCRP) and permanent teeth (2.7 $\pm 0.2 \%$ DPCs expressed BCRP) [41]. The expression of the $A B C G 2$ gene is evident in human DPCs cultured in keratinocyte growth medium $[9,64]$, and the rate of mRNA and protein expression has been shown to increase in human cultured DPCs under ischemic culture conditions [65]. However, in rat dental pulps, ABCG2 mRNA expression was decreased after tooth fracture induction, possibly due to the differentiation of stem cells following this insult [66]. Even though SP cells of the dental pulp have been described as a homogenous population [39], their heterogeneous nature is becoming apparent and needs to be elucidated.

\section{Final Comments on the Side Population Assay}

The SP assay is a very sensitive but highly technical assay. Dye efflux is a dynamic process, and slight variations in tissue dissociation, cell preparation and counting, dye concentrations, staining time, temperature, the stringency of the gating strategies, and selection of the SP cells by flow cytometry can dramatically affect the viability, homogeneity, and SP cell yield $[10,11,30]$. A great deal of variation is evident when published SP data is scrutinized. Lin and Goodell [32] clearly state that the SP assay is sensitive to slight modifications leading to variable SP results from person to person and one laboratory to another [32]. Golebiewska et al. [11] also highlighted the importance of improving the reproducibility of SP results between laboratories and standardizing data reporting for the SP assay [11].

In summary, the SP assay should not be considered as a definite characteristic of stem cells but rather as a useful purification strategy for isolating apparently more primitive cells from the main heterogeneous population. This was well illustrated by Wilson et al. [67] who compared different purification strategies for the enrichment of mHSCs using single-cell analysis [67]. Their findings showed that all purification strategies, including the SP assay, resulted in a heterogeneous population of cells with differences in engraftment potential [67]. To truly understand the heterogeneity of stem or stromal cell populations, other techniques will be required.

\section{Conflicts of Interest}

The authors have no conflicts of interest to declare.

\section{Acknowledgments}

This research was funded by the South African Medical Research Council in terms of the SAMRC's Flagship Award Project [SAMRC-RFA-UFSP-01-2013/STEM CELLS], the
SAMRC Extramural Unit for Stem Cell Research and Therapy, and the Institute for Cellular and Molecular Medicine of the University of Pretoria.

\section{References}

[1] H. M. Blau, T. R. Brazelton, and J. M. Weimann, "The evolving concept of a stem cell: entity or function?," Cell, vol. 105, no. 7, pp. 829-841, 2001.

[2] P. Bourin, B. A. Bunnell, L. Casteilla et al., "Stromal cells from the adipose tissue-derived stromal vascular fraction and culture expanded adipose tissue-derived stromal/stem cells: a joint statement of the International Federation for Adipose Therapeutics and Science (IFATS) and the International Society for Cellular Therapy (ISCT)," Cytotherapy, vol. 15, no. 6, pp. 641-648, 2013.

[3] J. M. Gimble, A. J. Katz, and B. A. Bunnell, "Adipose-derived stem cells for regenerative medicine," Circulation Research, vol. 100, no. 9, pp. 1249-1260, 2007.

[4] M. M. Mihaylova, D. M. Sabatini, and Ö. H. Yilmaz, "Dietary and metabolic control of stem cell function in physiology and cancer," Cell Stem Cell, vol. 14, no. 3, pp. 292-305, 2014.

[5] C. A. Ramos, T. A. Venezia, F. A. Camargo, and M. A. Goodell, "Techniques for the study of adult stem cells: be fruitful and multiply," BioTechniques, vol. 34, no. 3, pp. 572-591, 2003.

[6] T. Reya, S. J. Morrison, M. F. Clarke, and I. L. Weissman, "Stem cells, cancer, and cancer stem cells," Nature, vol. 414, no. 6859 , pp. 105-111, 2001.

[7] T. Lin, O. Islam, and K. Heese, "ABC transporters, neural stem cells and neurogenesis-a different perspective," Cell Research, vol. 16, no. 11, pp. 857-871, 2006.

[8] F. Ferraro, C. L. Celso, and D. Scadden, "Adult stem cells and their niches," Advances in Experimental Medicine and Biology, vol. 695, pp. 155-168, 2010.

[9] J. Wang, X. Wei, J. Ling, Y. Huang, Q. Gong, and Y. Huo, "Identification and characterization of side population cells from adult human dental pulp after ischemic culture," Journal of Endodontia, vol. 38, no. 11, pp. 1489-1497, 2012.

[10] G. A. Challen and M. H. Little, "A side order of stem cells: the SP phenotype," Stem Cells, vol. 24, no. 1, pp. 3-12, 2006.

[11] A. Golebiewska, N. H. C. Brons, R. Bjerkvig, and S. P. Niclou, "Critical appraisal of the side population assay in stem cell and cancer stem cell research," Cell Stem Cell, vol. 8, no. 2, pp. 136147, 2011.

[12] M. A. Goodell, K. Brose, G. Paradis, A. S. Conner, and R. C. Mulligan, "Isolation and functional properties of murine hematopoietic stem cells that are replicating in vivo," The Journal of Experimental Medicine, vol. 183, no. 4, pp. 1797-1806, 1996.

[13] C. W. Scharenberg, "The ABCG2 transporter is an efficient Hoechst 33342 efflux pump and is preferentially expressed by immature human hematopoietic progenitors," Blood, vol. 99, no. 2, pp. 507-512, 2002.

[14] C. M. Pule, S. L. Sampson, R. M. Warren et al., "Efflux pump inhibitors: targeting mycobacterial efflux systems to enhance TB therapy," The Journal of Antimicrobial Chemotherapy, vol. 71, no. 1, pp. 17-26, 2015.

[15] M. Falasca and K. J. Linton, "Investigational ABC transporter inhibitors," Expert Opinion on Investigational Drugs, vol. 21, no. 5, pp. 657-666, 2012. 
[16] M. Huls, F. G. M. Russel, and R. Masereeuw, "The role of ATP binding cassette transporters in tissue defense and organ regeneration," The Journal of Pharmacology and Experimental Therapeutics, vol. 328, no. 1, pp. 3-9, 2009.

[17] M. Dean, Y. Hamon, and G. Chimini, "The human ATPbinding cassette (ABC) transporter superfamily," Journal of Lipid Research, vol. 42, no. 7, pp. 1007-1017, 2001.

[18] G. D. Leonard, T. Fojo, and S. E. Bates, "The role of ABC transporters in clinical practice," The Oncologist, vol. 8, no. 5, pp. 411-424, 2003.

[19] G. Mamo and A. Pandi, "A review on ATP binding cassette (ABC) transporters," International Journal Of Pharma Research And Health Sciences, vol. 5, no. 2, pp. 1607-1615, 2017.

[20] Z. Erdei, R. Lörincz, K. Szebényi et al., "Expression pattern of the human ABC transporters in pluripotent embryonic stem cells and in their derivatives," Cytometry. Part B, Clinical Cytometry, vol. 86, no. 5, pp. 299-310, 2014.

[21] K. D. Bunting, S. Zhou, T. Lu, and B. P. Sorrentino, "Enforced P-glycoprotein pump function in murine bone marrow cells results in expansion of side population stem cells in vitro and repopulating cells in vivo," Blood, vol. 96, no. 3, pp. 902-909, 2000.

[22] C. H. Choi, “ABC transporters as multidrug resistance mechanisms and the development of chemosensitizers for their reversal," Cancer Cell International, vol. 5, no. 1, pp. 30-43, 2005.

[23] A. H. Schinkel and J. W. Jonker, "Mammalian drug efflux transporters of the ATP binding cassette (ABC) family: an overview," Advanced Drug Delivery Reviews, vol. 55, no. 1, pp. 3-29, 2003.

[24] S. Zhou, J. D. Schuetz, K. D. Bunting et al., "The ABC transporter Bcrp1/ABCG2 is expressed in a wide variety of stem cells and is a molecular determinant of the side-population phenotype," Nature Medicine, vol. 7, no. 9, pp. 1028-1034, 2001.

[25] U. Lindner, J. Kramer, J. Rohwedel, and P. Schlenke, "Mesenchymal stem or stromal cells: toward a better understanding of their biology?", Transfusion Medicine and Hemotherapy, vol. 37, no. 2, pp. 75-83, 2010.

[26] S. Perrini, R. Ficarella, E. Picardi et al., "Differences in gene expression and cytokine release profiles highlight the heterogeneity of distinct subsets of adipose tissue-derived stem cells in the subcutaneous and visceral adipose tissue in humans," PLoS One, vol. 8, no. 3, pp. e57892-e57905, 2013.

[27] R. Barbet, I. Peiffer, J. R. A. Hutchins, A. Hatzfeld, E. Garrido, and J. A. Hatzfeld, "Expression of the 49 human ATP binding cassette $(\mathrm{ABC})$ genes in pluripotent embryonic stem cells and in early- and late-stage multipotent mesenchymal stem cells: Possible role of ABC plasma membrane transporters in maintaining human stem cell pluripotency," Cell Cycle, vol. 11, no. 8, pp. 1611-1620, 2012.

[28] D. D. Ross and T. Nakanishi, "Impact of breast cancer resistance protein on cancer treatment outcomes," Methods in Molecular Biology, vol. 596, pp. 251-290, 2010.

[29] D. C. Andersen, H. D. Schrøder, and C. H. Jensen, "Noncultured adipose-derived $\mathrm{CD}^{\circ} 5^{-}$side population cells are enriched for progenitors that give rise to myofibres in vivo," Experimental Cell Research, vol. 314, no. 16, pp. 2951-2964, 2008.

[30] H. Masuda, T. Maruyama, C. E. Gargett et al., "Endometrial side population cells: potential adult stem/progenitor cells in endometrium," Biology of Reproduction, vol. 93, no. 4, p. 84, 2015.

[31] H. Zeng, J. W. Park, M. Guo et al., "Lack of ABCG2 expression and side population properties in human pluripotent stem cells," Stem Cells, vol. 27, no. 10, pp. 2435-2445, 2009.

[32] K. K. Lin and M. A. Goodell, "Purification of hematopoietic stem cells using the side population," Methods in Enzymology, vol. 420, pp. 255-264, 2006.

[33] K. Parmar, C. Sauk-Schubert, D. Burdick, M. Handley, and P. Mauch, "Sca ${ }^{+} \mathrm{CD} 34^{-}$murine side population cells are highly enriched for primitive stem cells," Experimental Hematology, vol. 31, no. 3, pp. 244-250, 2003.

[34] P. Brunet de la Grange, M. Vlaski, P. Duchez et al., "Long-term repopulating hematopoietic stem cells and "side population" in human steady state peripheral blood," Stem Cell Research, vol. 11, no. 1, pp. 625-633, 2013.

[35] R. W. Storms, M. A. Goodell, A. Fisher, R. C. Mulligan, and C. Smith, "Hoechst dye efflux reveals a novel $\mathrm{CD} 7^{+} \mathrm{CD} 34^{-}$ lymphoid progenitor in human umbilical cord blood," Blood, vol. 96, no. 6, pp. 2125-2133, 2000.

[36] R. Ishizaka, K. Iohara, M. Murakami, O. Fukuta, and M. Nakashima, "Regeneration of dental pulp following pulpectomy by fractionated stem/progenitor cells from bone marrow and adipose tissue," Biomaterials, vol. 33, no. 7, pp. 21092118, 2012.

[37] T. Schumacher, M. Krohn, J. Hofrichter et al., "ABC transporters $\mathrm{B} 1, \mathrm{C} 1$ and $\mathrm{G} 2$ differentially regulate neuroregeneration in mice," PLoS One, vol. 7, no. 4, pp. e35613-e35627, 2012.

[38] A. Asakura and M. A. Rudnicki, "Side population cells from diverse adult tissues are capable of in vitro hematopoietic differentiation," Experimental Hematology, vol. 30, no. 11, pp. 1339-1345, 2002.

[39] K. Iohara, L. Zheng, M. Ito, A. Tomokiyo, K. Matsushita, and M. Nakashima, "Side population cells isolated from porcine dental pulp tissue with self-renewal and multipotency for dentinogenesis, chondrogenesis, adipogenesis, and neurogenesis," Stem Cells, vol. 24, no. 11, pp. 2493-2503, 2006.

[40] Y. Hayashi, M. Murakami, R. Kawamura, R. Ishizaka, O. Fukuta, and M. Nakashima, "CXCL14 and MCP1 are potent trophic factors associated with cell migration and angiogenesis leading to higher regenerative potential of dental pulp side population cells," Stem Cell Research \& Therapy, vol. 6, no. 1, pp. 111-119, 2015.

[41] J. Wang, X. Wei, J. Ling, Y. Huang, Y. Huo, and Y. Zhou, "The presence of a side population and its marker ABCG2 in human deciduous dental pulp cells," Biochemical and Biophysical Research Communications, vol. 400, no. 3, pp. 334-339, 2010.

[42] M. J. Honda, F. Nakashima, K. Satomura et al., "Side population cells expressing ABCG2 in human adult dental pulp tissue," International Endodontic Journal, vol. 40, no. 12, pp. 949-958, 2007.

[43] C. M. Martin, A. P. Meeson, S. M. Robertson et al., "Persistent expression of the ATP-binding cassette transporter, Abcg2, identifies cardiac SP cells in the developing and adult heart," Developmental Biology, vol. 265, no. 1, pp. 262-275, 2004.

[44] O. Pfister, A. Oikonomopoulos, K. I. Sereti et al., "Role of the ATP-binding cassette transporter Abcg2 in the phenotype and function of cardiac side population cells," Circulation Research, vol. 103, no. 8, pp. 825-835, 2008. 
[45] A. M. Hierlihy, et al.P. Seale, C. G. Lobe, M. A. Rudnicki, and L. A. Megeney, "The post-natal heart contains a myocardial stem cell population," FEBS Letters, vol. 530, no. 1-3, pp. 239-243, 2002.

[46] T. L. Hackett, F. Shaheen, A. Johnson et al., "Characterization of side population cells from human airway epithelium," Stem Cells, vol. 26, no. 10, pp. 2576-2585, 2008.

[47] S. M. Majka, M. A. Beutz, M. Hagen, A. A. Izzo, N. Voelkel, and K. M. Helm, "Identification of novel resident pulmonary stem cells: form and function of the lung side population," Stem Cells, vol. 23, no. 8, pp. 1073-1081, 2005.

[48] C. M. Penton, J. M. Thomas-Ahner, E. K. Johnson, C. McAllister, and F. Montanaro, "Muscle side population cells from dystrophic or injured muscle adopt a fibro-adipogenic fate," PLoS One, vol. 8, no. 1, pp. e54553-e54565, 2013.

[49] A. Asakura, P. Seale, A. Girgis-Gabardo, and M. A. Rudnicki, "Myogenic specification of side population cells in skeletal muscle," The Journal of Cell Biology, vol. 159, no. 1, pp. 123134, 2002.

[50] E. Gussoni, Y. Soneoka, C. D. Strickland et al., "Dystrophin expression in the mdx mouse restored by stem cell transplantation," Nature, vol. 401, no. 6751, pp. 390-394, 1999.

[51] K. A. Jackson, T. Mi, and M. A. Goodell, "Hematopoietic potential of stem cells isolated from murine skeletal muscle," Proceedings of the National Academy of Sciences of the United States of America, vol. 96, no. 25, pp. 14482-14486, 1999.

[52] C. B. Sayre and F. J. Silva, "Adipose-derived stem cells for tissue regeneration and wound Healing," US Patent 8119398B2, 2012.

[53] T. V. Ramos, T. Wang, C. B. Maki, M. Pascual, and F. Izadyar, "Adipose stem cell side population in the mouse," Journal of Tissue Engineering and Regenerative Medicine, vol. 3, no. 6, pp. 430-441, 2009.

[54] P. Supronowicz, E. Gill, A. Trujillo et al., "Human adiposederived side population stem cells cultured on demineralized bone matrix for bone tissue engineering," Tissue Engineering. Part A, vol. 17, no. 5-6, pp. 789-798, 2011.

[55] A. Terunuma, K. L. Jackson, J. C. Vogel, V. Kapoor, and W. G. Telford, "Side population keratinocytes resembling bone marrow side population stem cells are distinct from label-retaining keratinocyte stem cells," The Journal of Investigative Dermatology, vol. 121, no. 5, pp. 1095-1103, 2003.

[56] K. Kato, M. Yoshimoto, K. Kato et al., "Characterization of side-population cells in human normal endometrium," Human Reproduction, vol. 22, no. 5, pp. 1214-1223, 2007.

[57] C. Li and G. Johnson, "Rhodamine123 reveals heterogeneity within murine Lin-, Sca-1+ hemopoietic stem cells," The Journal of Experimental Medicine, vol. 175, no. 6, pp. 1443-1447, 1992.

[58] N. Wolf, A. Koné, G. V. Priestley, and S. H. Bartelmez, "In vivo and in vitro characterization of long-term repopulating primitive hematopoietic cells isolated by sequential Hoechst 33342rhodamine 123 FACS selection," Experimental Hematology, vol. 21, no. 5, pp. 614-622, 1993.

[59] A. Bourdieu, M. Avalon, V. Lapostolle et al., "Steady state peripheral blood provides cells with functional and metabolic characteristics of real hematopoietic stem cells," Journal of Cellular Physiology, vol. 233, no. 1, pp. 338-349, 2018.

[60] P. Bora and A. S. Majumdar, "Adipose tissue-derived stromal vascular fraction in regenerative medicine: a brief review on biology and translation," Stem Cell Research \& Therapy, vol. 8, no. 1, pp. 145-155, 2017.
[61] Y. Du, D. S. Roh, M. L. Funderburgh et al., "Adipose-derived stem cells differentiate to keratocytes in vitro," Molecular Vision, vol. 16, pp. 2680-2689, 2010.

[62] R. Ishizaka, Y. Hayashi, K. Iohara et al., "Stimulation of angiogenesis, neurogenesis and regeneration by side population cells from dental pulp," Biomaterials, vol. 34, no. 8, pp. 1888-1897, 2013.

[63] K. Ito, K. Matsuoka, K. Matsuzaka, K. Morinaga, and T. Inoue, "Hypoxic condition promotes differentiation and mineralization of dental pulp cells in vivo," International Endodontic Journal, vol. 48, no. 2, pp. 115-123, 2015.

[64] H. Nam and G. Lee, "Identification of novel epithelial stem cell-like cells in human deciduous dental pulp," Biochemical and Biophysical Research Communications, vol. 386, no. 1, pp. 135-139, 2009.

[65] J. Wang, X. Wei, J. Ling, Y. Huang, and Q. Gong, "Side population increase after simulated transient ischemia in human dental pulp cell," Journal of Endodontia, vol. 36, no. 3, pp. 453-458, 2010.

[66] H. Shima, K. Matsuzaka, E. Kokubu, and T. Inoue, "Regenerative capability of dental pulp cells after crown fracture," Dental Traumatology, vol. 29, no. 1, pp. 29-33, 2013.

[67] N. K. Wilson, D. G. Kent, F. Buettner et al., "Combined singlecell functional and gene expression analysis resolves heterogeneity within stem cell populations," Cell Stem Cell, vol. 16, no. 6, pp. 712-724, 2015. 


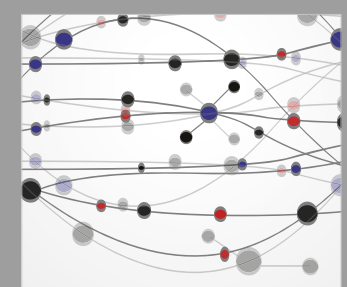

The Scientific World Journal
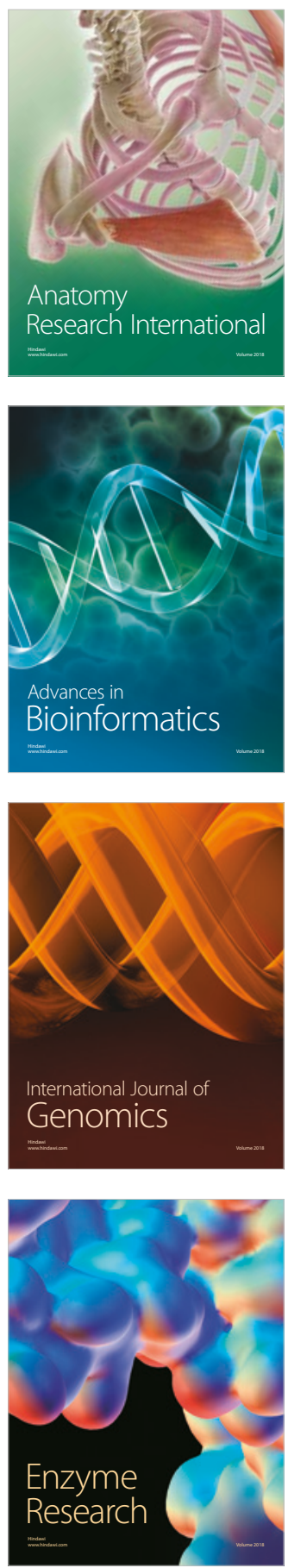
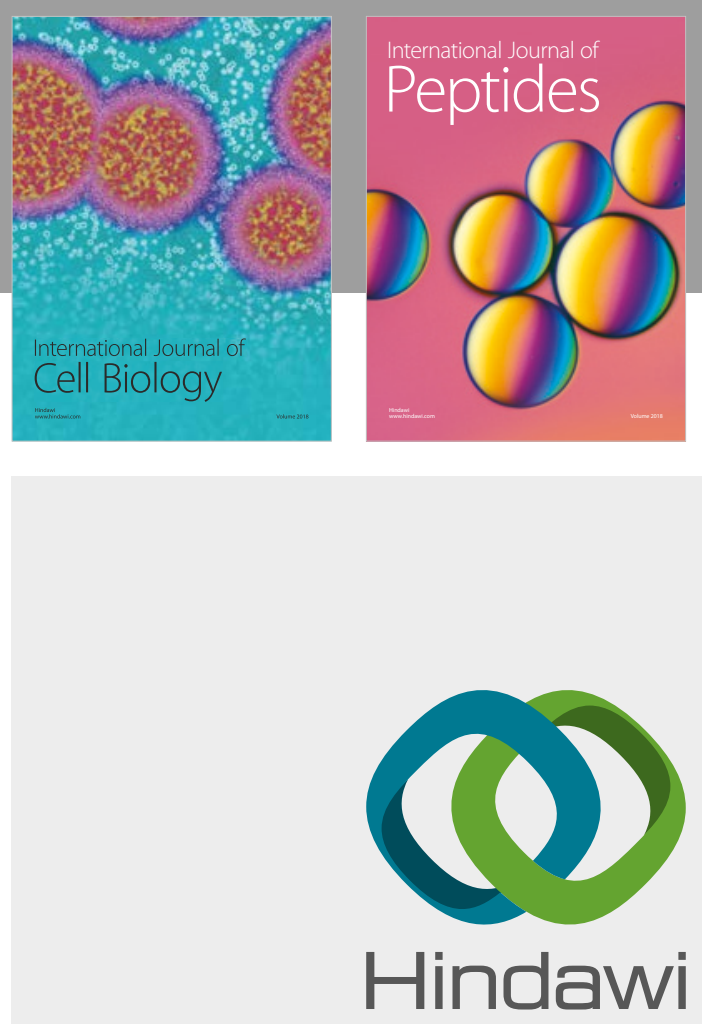

Submit your manuscripts at

www.hindawi.com
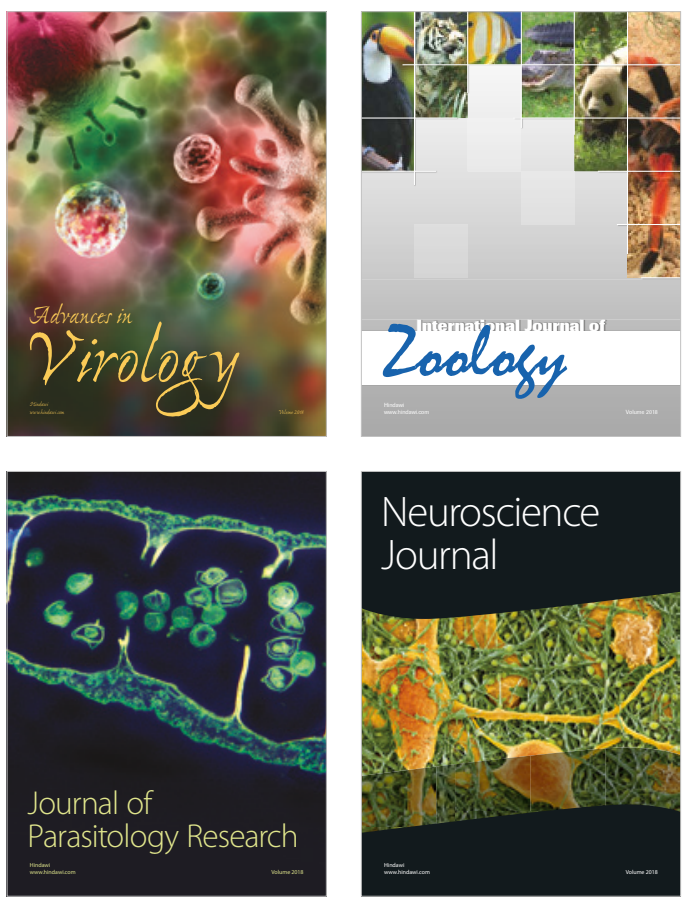
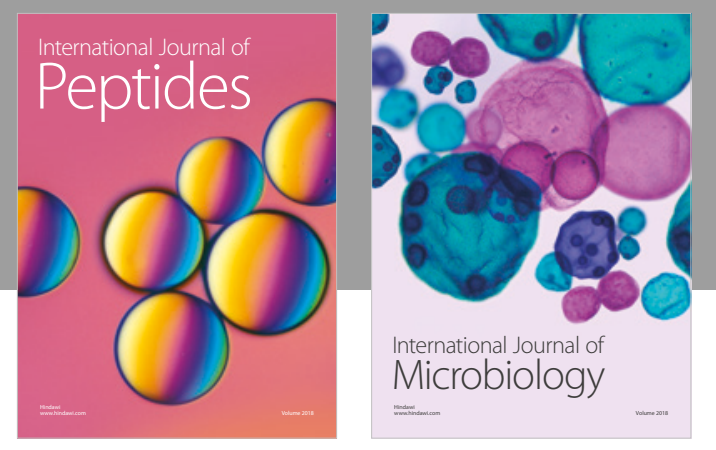

nternational Journal of Microbiology
Journal of
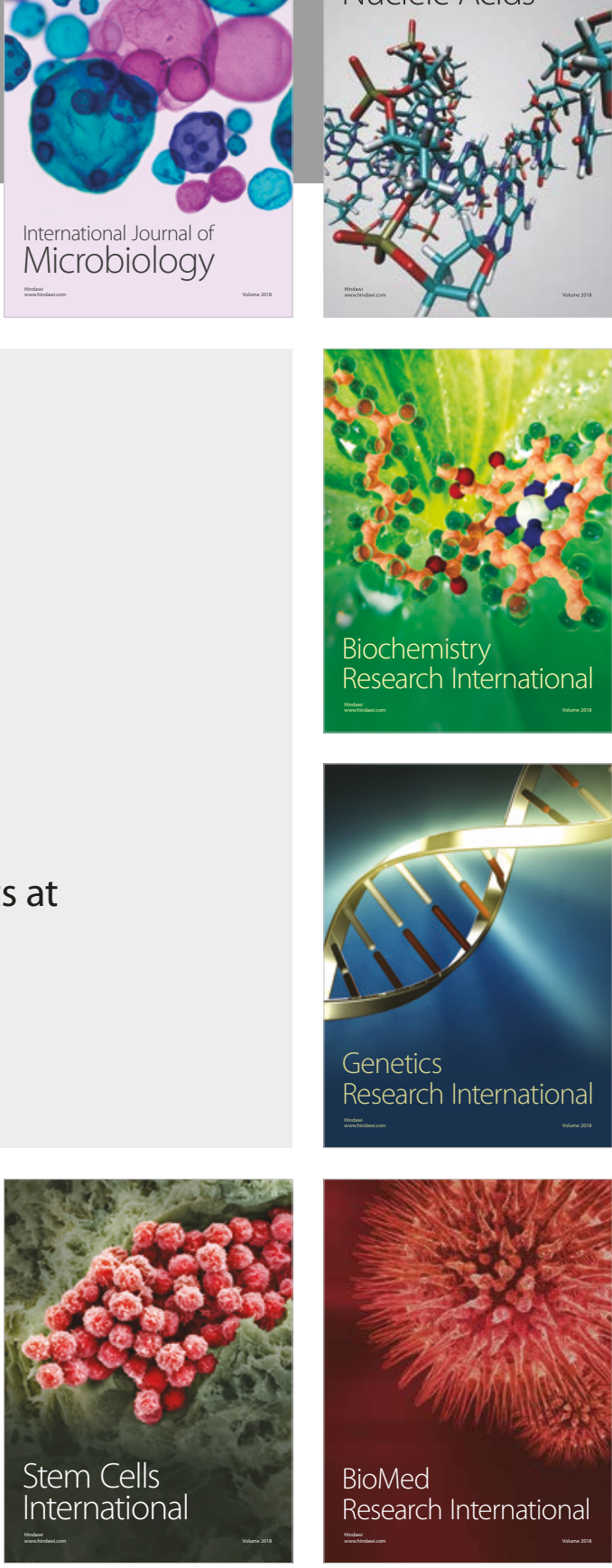
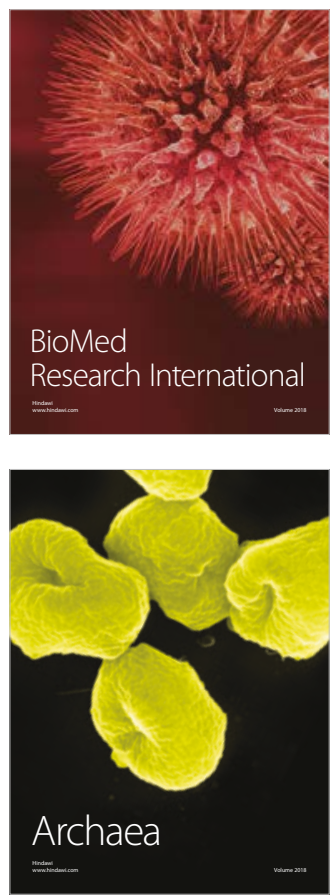